\title{
Identification of Flow Channels using Streamline Numerical Simulation and Fuzzy Comprehensive Evaluation
}

\author{
Zhichao Zhang, a , Mingxing Bai, ${ }^{1,}$, Yan $\mathrm{Li}^{2, \mathrm{c}}$ \\ ${ }^{1}$ Department of Petroleum Engineering, Northeast Petroleum University, 163318, Daqing, China \\ ${ }^{2}$ Oil Plant 1, Henan Oilfield, SINOPEC, 474750, Tongbai, China

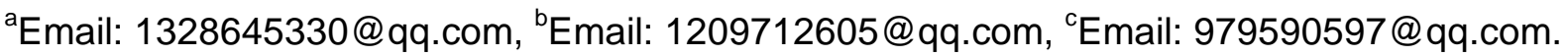

Keywords: Streamline Numerical Simulation Distribution factor of injection Well Water injection efficiency Fuzzy comprehensive evaluation Advantaged flow field

Abstract. Analyzing the flow channels between production wells and injection wells is very important to develop an oil field. For the oilfield D, the streamline numerical simulation method is adopted to output the flow line distribution, the allocation factor graph of injection wells, and water injection efficiency graph between two wells. At the end, the fuzzy comprehensive evaluation technique is also used to verify the results in the oilfield.

\section{Introduction}

The traditional methods of identifying the advantaged flow field include geology analysis, log interpretation, dynamic analysis, isotope tracer method, and so on. The authors take streamline-based flow simulation method and fuzzy comprehensive evaluation to identify the distribution of 3D flow field between the oil wells and the water wells in D Oilfield. Identifying the advantaged flow field by fuzzy comprehensive evaluation method is to consider the comprehensive impact by a variety of factors ${ }^{[1]}$. We choose the appropriate fuzzy transformation membership function to transform each non-linear factor into linear relationship factors which is related to advantaged flow field. Then we transform these factors by next step fuzzy transformation until the end of the fuzzy transformation.

\section{Analyzing the advantaged flow field by the Streamline numerical simulation}

\section{Analysis the advantaged flow field by the Three-dimensional Streamline FIG}

It can be seen from the 3D visualization of the streamline shown in Figure 1, the streamline is thick between the injection well of WT4-807 and the production well of 4-907 in VII9 layer. The same situation occurred between WJ4-107 injection well and 4-12, 5-127 Production well. So we can make the conclusion that most of injected water flows into the production wells along the advantaged flow field direction and finally leads to the invalid water flow channel.

\section{Study the advantaged flow field by the injection well factor chart}

The distribution file that output by the results of streamline simulation provides the yield of water that distribute to each effective oil well. So we get the water injection assignment Table1 of WT4-807 and J4-107 wells and draw the distribution factor Chart 3. What can be seen from the distribution factor figure is that there is advantaged flow field between the injection well WT4-807 and the production well 4-907, so we can analyze the advantaged flow field in VII9 layer by the injection well factor chart combined with streamline distribution diagram. 


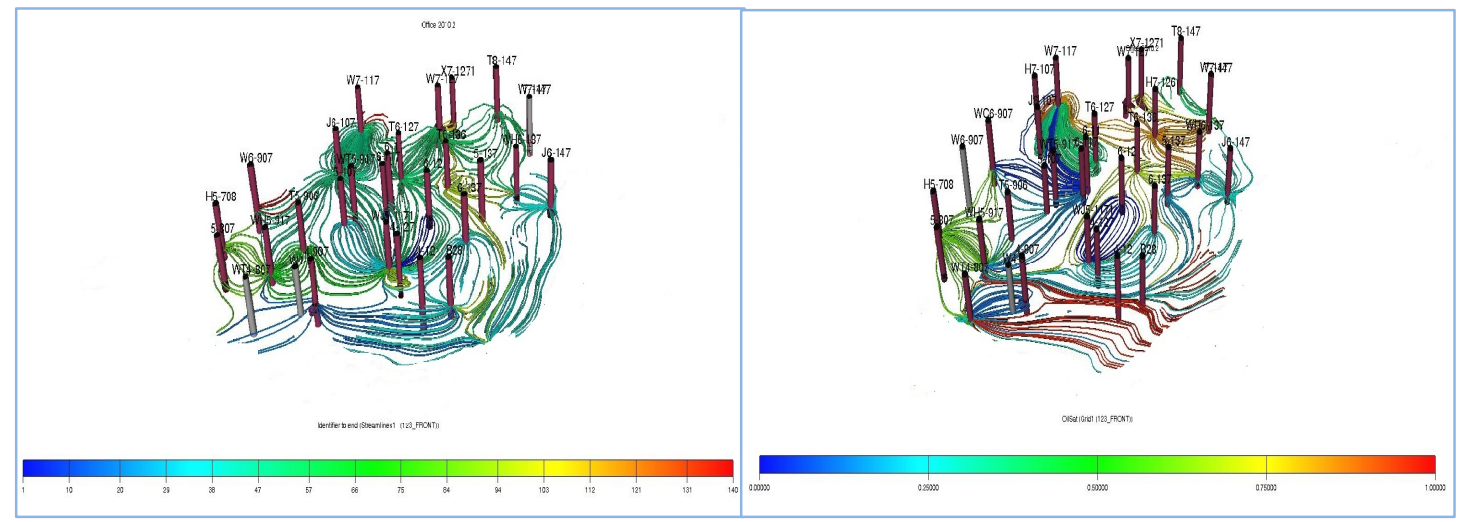

Fig. 1 Streamline distribution（YEAR:2001） Figure 2 Streamline distribution（YEAR:2015)

Table 1 water injection factor table of WT4-807 and WJ4-107

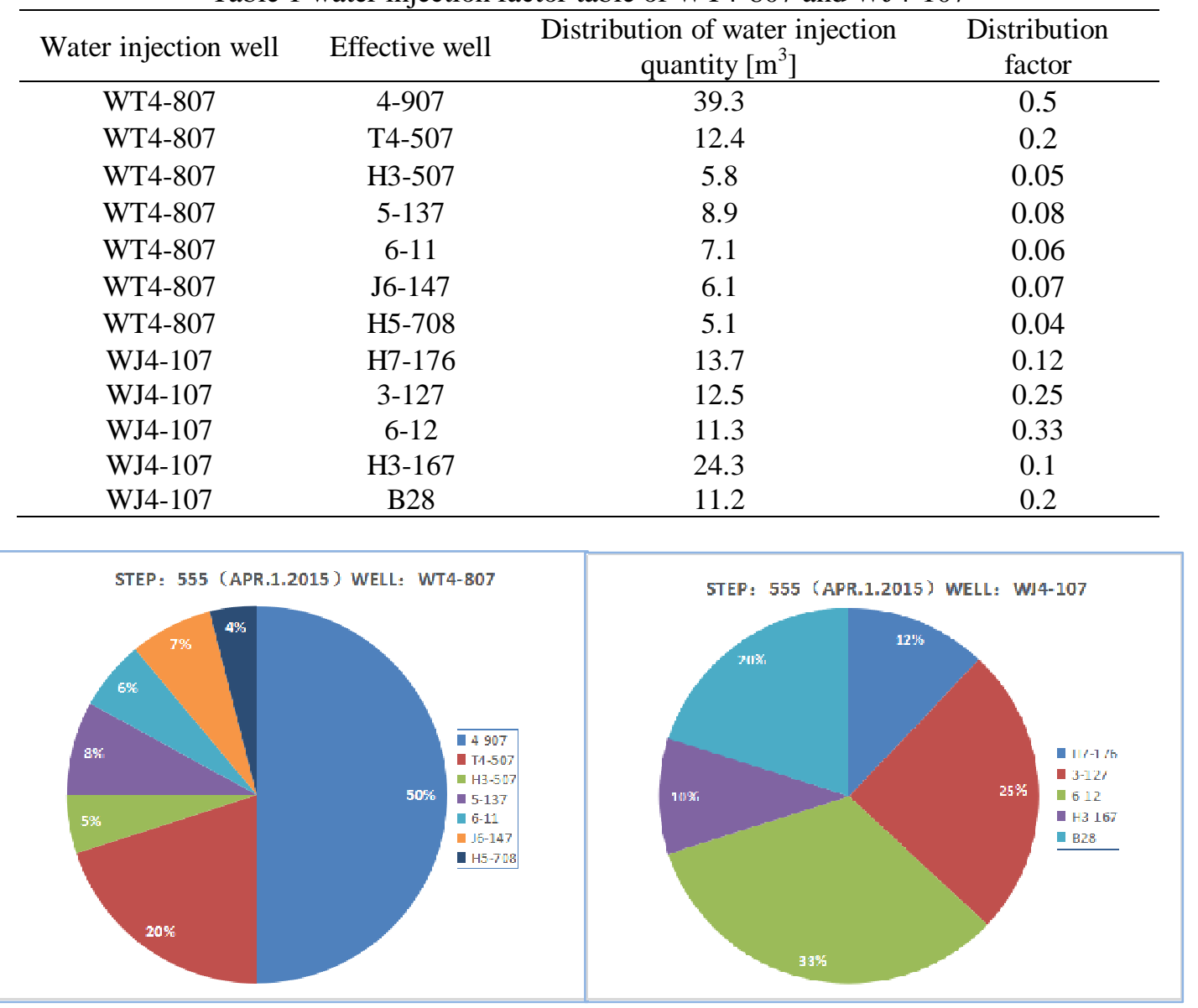

Fig.2 The distribution factor chart of WT4-807 and WJ4-107

\section{Determination of the advantaged flow field by water injection efficiency chart}

The water injection efficiency of each injection well is calculated by streamline numerical simulation ${ }^{[2]}$. The daily injection quantity of each injection well is defined as the $\mathrm{X}$ coordinate ${ }^{[3-4]}$, The daily oil production of every production well related to the injection well is taken as Y coordinate. We define the futile cycle injection wells as water injection efficiency is less than $50 \%$. I found only two wells' water efficiency (WH5-137 and WF8-19) is greater than 50\% by calculating 32 injection wells efficiency on the region. The efficiency of other 30 injection wells is all lower than $25 \%$. It shows that these water injection wells have advantaged flow channel in some direction to a production well. The Water injection efficiency chart is shown as Fig 3. 


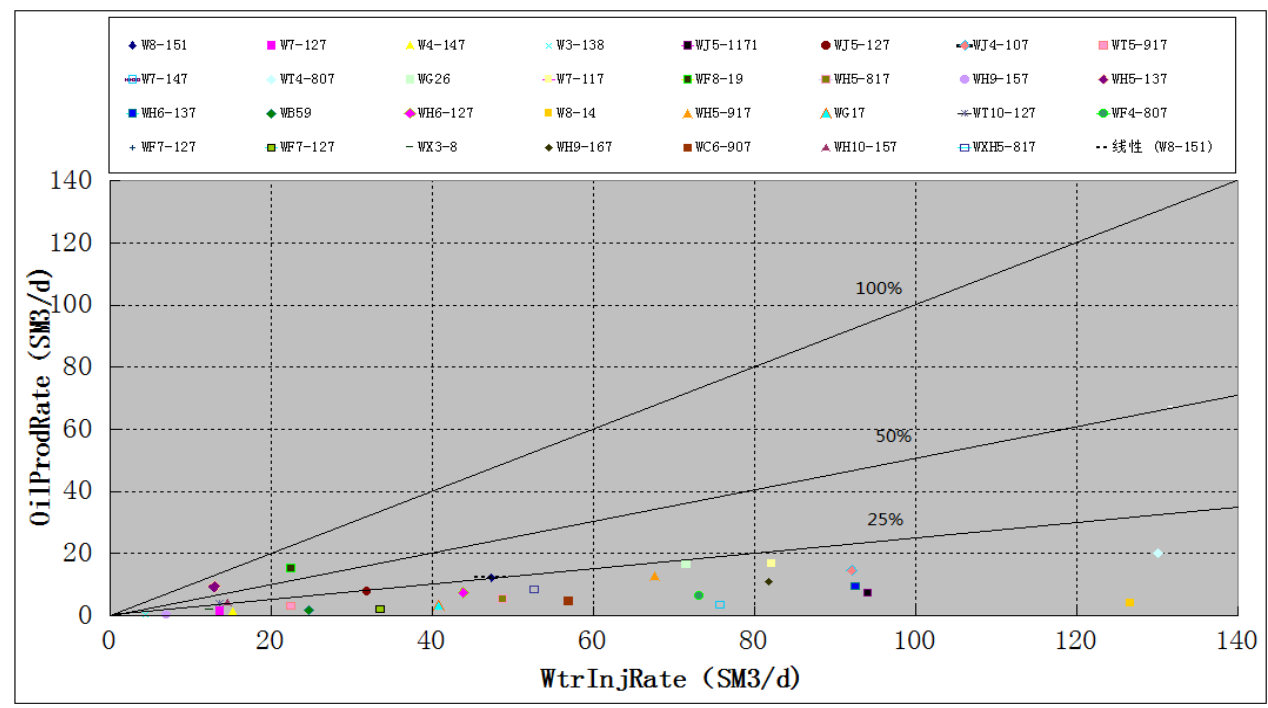

Fig. 3 Injection wells' efficiency of D oilfield VII strata

\section{Determining the advantaged flow field by fuzzy comprehensive evaluation}

The WT4-807 well group is selected as an example to study the flow channels by fuzzy comprehensive evaluation. Fuzzy comprehensive evaluation procedure is as follows.

(1) Dynamic and static parameters of Well group WT4-807 is shown in Table 2 and 3.

Table 2 The parameter of WT4-807 wells

\begin{tabular}{c|c|c|c|c|c|c}
\hline $\begin{array}{c}\text { Number of } \\
\text { well }\end{array}$ & $\begin{array}{c}\text { Permeability } \\
{\left[\times 10^{-3} \mu \mathrm{m}^{2}\right]}\end{array}$ & $\begin{array}{c}\text { Porosity } \\
{[\%]}\end{array}$ & $\begin{array}{c}\text { Small } \\
\text { thickness } \\
{[\mathrm{m}]}\end{array}$ & $\begin{array}{c}\text { Water } \\
\text { injection } \\
\text { pressure } \\
{[\mathrm{MPa}]}\end{array}$ & $\begin{array}{c}\text { Daily water } \\
\text { injection } \\
{\left[\mathrm{m}^{3}\right]}\end{array}$ & $\begin{array}{c}\text { Water injection } \\
\text { intensity } \\
{\left[10^{4} \mathrm{~m}^{3} / \mathrm{m}\right]}\end{array}$ \\
\hline WT4-807 & 120 & 20 & 34 & 20.7 & 21.42 & 0.63 \\
\hline
\end{tabular}

Table 3 The parameter of $4-907$ wells

\begin{tabular}{c|c|c|c|c}
\hline $\begin{array}{c}\text { Number of } \\
\text { well }\end{array}$ & $\begin{array}{c}\text { Permeability } \\
{\left[\times 10^{-3} \mu \mathrm{m}^{2}\right]}\end{array}$ & $\begin{array}{c}\text { Small thickness } \\
{[\mathrm{m}]}\end{array}$ & $\begin{array}{c}\text { Water cut } \\
{[\%]}\end{array}$ & $\begin{array}{c}\text { Daily liquid rate } \\
{\left[\mathrm{m}^{3} / \mathrm{d}\right]}\end{array}$ \\
\hline $4-907$ & 164 & 45.8 & 92.7 & 214.2 \\
\hline
\end{tabular}

(2) Selecting the membership function of wells

It is found that the indicators obey normal distribution by inductive analysis of actual data of the major strata of D oil field VII strata, so I select the normal distribution function as membership function. The normal distribution function is shown in Equation 1:

$$
u_{y}(x)=e^{-[(x-a) / b]^{2}}
$$

where $x$ : evaluation factor, $y:$ comment grade, $a, b$ : index.

(3) Determination of the fuzzy comprehensive judgment matrix above two wells

The fuzzy relationship matrix of well group WT4-807 is obtained by taking the dynamic and static parameters of injection well WT4-807 and production well 4-907 into above membership Eq1. respectively. The matrix for the injection is listed in R1 and R2 as an example.

$$
\mathbf{R}_{\mathbf{1}}=\left[\begin{array}{lll}
0.000243351 & 0.885196987 & 6.13638 \mathrm{E}-06 \\
0.681877851 & 6.32076 \mathrm{E}-15 & 2.60445 \mathrm{E}-17 \\
0.629977385 & 6.32076 \mathrm{E}-15 & 2.60445 \mathrm{E}-17
\end{array}\right] \text { permeability }
$$

Invalid circulation low efficiency circulation normal production

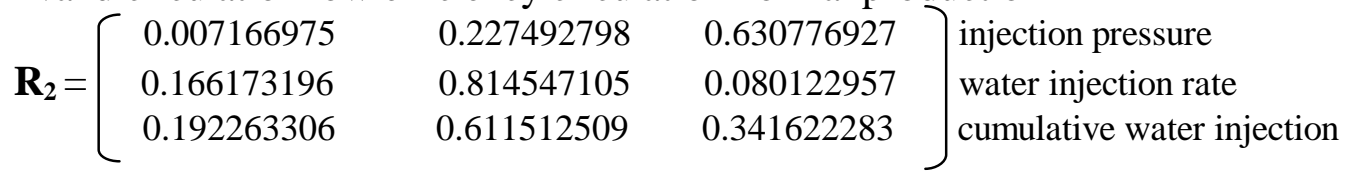


(4)Determination of the weight of static and dynamic parameters of WT4-807 well group

I give dynamic and static factor index weight composition weight Table of WT4-807 well and 4-907 well by related Expert's advice and analytic hierarchy process and the weight composition weight as table 4 and $5^{[5]}$.

Table 4 The injection and production well parameters

\begin{tabular}{|c|c|c|c|}
\hline & & Injection well & Production well \\
\hline \multirow{3}{*}{$\begin{array}{l}\text { Static } \\
\text { factors }\end{array}$} & \multirow{3}{*}{0.35} & permeability: 0.35 & The permeability of well: 0.6 \\
\hline & & Effective thickness: 0.3 & Effective thickness: 0.4 \\
\hline & & Porosity: 0.35 & Liquid production rate: 0.5 \\
\hline \multirow{3}{*}{$\begin{array}{l}\text { Dynamic } \\
\text { factors }\end{array}$} & \multirow{3}{*}{0.65} & injection pressure: 0.2 & Water cut: 0.5 \\
\hline & & water injection rate: 0.4 & The permeability of well: 0.6 \\
\hline & & Cumulative water injection: 0.4 & Effective thickness: 0.4 \\
\hline
\end{tabular}

(5) Variety of factors fuzzy transformation to determine the advantaged flow field

By multiplying the fuzzy relation matrix and the weight matrix one can get the fuzzy evaluation results of injection well WT4-807 and production well 4-907 (B1, B2), where B1 $=(0.23,0.503,0.19)$, $\mathrm{B} 2=(0.27,0.23,0.21)$. One can get the conclusion that the well WT4-807 is invalid injection well and the well 4-907 is invalid production well.

\section{Conclusions}

(1) One can judge the flow channels by combining the streamline numerical simulation method and fuzzy comprehensive evaluation. The former gives the 3D streamline distribution in each layer, allocation factor between injection and production wells so that the flow channels can be identified.

(2) Both methods give similar results. However, the streamline numerical simulation is more intuitive and it can provide very meaningful guidance to exploit the remaining oil.

\section{Acknowledgements}

This work was financially supported by the PetroChina Innovation Foundation (Grant No.: 2015D-5006-0202) and Heilongjiang Postdoctoral Grant (Investigation of the THMC Coupling Effect on $\mathrm{CO}_{2}$ Migration along Casing-cement-rock Composite System).

\section{References}

[1] T. Xu and R. G. Bea: International Society of Offshore and Polar Engineers (1992).

[2] M. Bostan, R. Kharrat: Implementing a Novel Method for Injection Efficiency Optimization in Water Flooding Process: Case Study. This paper was prepared for presentation at the SPE Production and Operations Symposium held in Oklahoma City, Oklahoma, USA, 27-29 March 2011.

[3] AI. Najem, A.A. Siddiqui and S. Soliman etc.: Yuen: Streamline Simulation Technology: Evolution and Recent Trends, This paper was prepared for presentation at the SPE Saudi Arabia Section Technical Symposium and Exhibition held in AI-Khobar, Saudi Arabia, 8-11 April 2012.

[4] R. Marco, Thiele, P. Rod: Water Injection Optimization Using a Streamline-Based Workflow, This paper was prepared for presentation at the SPE Annual Technical Conference and Exhibition held in Denver, Colorado, USA, 5-8 October 2003.

[5] Q. Zeng, Z. Wang and X. Wang etc.: Selection of Passive Inflow Control Devices Based on Dynamic Weight Fuzzy Evaluation. International Petroleum Technology Conference. doi: 10.2523/17794-MS, December, 2014. 